\title{
Aspectos mórfico-sintáticos e a funcionalidade do artigo como construtor do texto
}

DOI: http://dx.doi.org/10.21165/el.v49i2.2585

\author{
Nelyse Apparecida Melro Salzedas ${ }^{1}$ \\ Rivaldo Alfredo Paccola²
}

\section{Resumo}

O artigo é, dentre as categorias gramaticais, uma das mais expressivas, porém nem sempre explorado. Alguns autores tiram-no da passividade e dão-lhe um tom aguerrido e múltiplo. A presença do artigo definido traz reforço aos nomes abstratos pluralizados, acentuando-lhes a vaguidade; assim como sua omissão esvazia as arestas de nomes concretos, gerando sigmatização. O artigo cria também uma função rítmica e tem um papel intensificante em nível entoativo, uma vez que o acento tonal reforça o conteúdo substantivo. E um texto produzido por meio de uma pontuação lógica, ausente o sistema afetivo, traduz tons afetivos, tons intensivos, se manipuladas habilmente as estruturas mórfico-sintáticas. Sob a luz dos estudos de Macambira (1974), Cressot (1969), Borba (1971), Brik (1978), Paiva (1961), Pimpão (1942), propomos discutir o uso e a função do artigo sob o ponto de vista mórfico e sintático bem como sua funcionalidade dentro do texto: a superlativação, a enfatização, a entoação. Assim, a carta Ao Sr. E. Mollinet, na Correspondência de Fradique Mendes, de Eça de Queiroz (s/d), serviu de contexto para aplicação da teoria arrolada, posto que o uso eciano do artigo contextualiza situações que indicam as condições destacadas.

Palavras-chave: artigo; funcionalidade; sigmatização.

1 Universidade Estadual Paulista "Júlio de Mesquita Filho" (UNESP), Bauru, São Paulo, Brasil; nelysesalzedas@yahoo.com.br; http://orcid.org/0000-0002-5859-6391

2 Universidade Federal dos Vales do Jequitinhonha e Mucuri/Diamantina (UFVJM), Diamantina, Minas Gerais, Brasil, rivapaccola@terra.com.br, http://orcid.org/0000-0002-2792-2748 


\title{
Morphic-syntactic aspects and the functionality of the article as a text builder
}

\begin{abstract}
The article is one of the most expressive categories, but not always explored. Some authors take it out of passivity and give it a fierce and multiple tone. The presence of the definite article reinforces the pluralized abstract names, emphasizing their vagueness; just as its omission empties the edges of concrete names, generating sigmatization. The article also creates a rhythmic function and has an intensifying role at the intonative level, as the tonal accent reinforces the substantive content. And a text produced by a logical punctuation, absent the affective system, translates affective tones, intensive tones, if skillfully manipulated morphic-syntactic structures. In the light of studies by the following authors: Macambira (1974), Cressot (1969), Borba (1971), Brik (1978), Paiva (1961), Pimpão (1942), we propose to discuss the use and function of the article from the morphic and syntactic point of view as well as its functionality within the text: the superlativation, the emphasis, the intonation. Thus, the letter Ao Sr. E. Mollinet, in Correspondência de Fradique Mendes, by Eça de Queiroz (s/d), served as a context for the application of the listed theory, since the ecian use of the article contextualizes situations that indicate the highlighted conditions.
\end{abstract}

Keywords: article; functionality; sigmatization.

\section{Introdução}

Um livro isolado sobre estudos da língua, "A estrutura morfo-sintática do português: aplicação do estruturalismo linguístico", de José Rebouças Macambira, em sua $2^{a}$ edição, de 1974, pela Pioneira, ao ser aberto pelo leitor, vai possibilitar-Ihe encontrar os aspectos mórfico-sintáticos do artigo, o qual "não tem forma especial que o distinga como classe gramatical" (MACAMBIRA, 1974, p. 46).

Para elucidar esse categorema ${ }^{3}$, uma bibliografia a respeito é indicada: Macambira (1974), Cressot (1969), Borba (1971), Brik (1978), Paiva (1961) e Pimpão (1942).

Agora, o leitor instigado vai folhear os textos arrolados e encontrará:

Macambira (1974, p. 46) - Traz contribuições ao estudo do idioma tanto do ponto de vista mórfico, quanto sintático, à luz da linguística. Nas palavras do próprio autor, na

3 "Palavra que apenas tem significação categórica ou gramatical (q.v.), que apenas denota sem significar. Ex.: os advérbios, os pronomes, os artigos." (BORBA, 1971, p. 42). 
Introdução: "Não se trata de abolir a gramática tradicional, que tantos e tão bons serviços prestou e vem prestando ao estudo e ao ensino de línguas nacionais ou estrangeiras.". Por outro lado, entende o autor que seu trabalho cumpre e urge favorecer a gramática com as conquistas da linguística moderna. Divide-se em seis partes e um apêndice: Princípios Básicos, Classificação dos Vocábulos, A Estrutura Sintática do Português, Termos Essenciais da Oração, Termos Integrantes da Oração e Termos Acessórios da Oração (361 pp.).

Cressot (1969, p. 9) - Trata-se da 6a edição revista e aumentada por Laurence Gallo (a primeira é de 1947) da obra Le style et ses techniques: précis d'analyse stylistique, publicada por Presses Universitaires de France, na qual "a interpretação e o estudo de qualquer mensagem oral ou escrita remete-nos para a relação existente entre um pensamento e a sua expressão. Aí intervém a estilística como instrumento privilegiado de análise, em cuja metodologia convergem não só os fatores linguísticos, mas também os psicológicos e os sociais". Sumário: Prefácio de L.G.; Prefácio; Introdução; $1^{a}$ Parte - As palavras; $2^{a}$ Parte: Integração da palavra no pensamento; $3^{a}$ Parte: A frase; Conclusão; Bibliografia geral; Apêndice (350 pp.). Neste paper, ocupamo-nos da segunda parte, especialmente o primeiro capítulo: "Atualização e determinação", para discutir o Artigo.

Borba (1971) - O "Pequeno Vocabulário de Linguística Moderna" foi concebido para atender ao avanço dos estudos linguísticos da época, em razão da miríade terminológica, as diferentes acepções de um mesmo termo, por vezes diversa para diferentes escolas, bem como a diversificação das escolas linguísticas, gerando inquietante instabilidade de noções, em consequência dificultando a leitura e compreensão de livros e artigos especializados em linguística moderna. No prefácio, Isaac N. Salum (p. 18) menciona: "Mas é por ser um Pequeno Vocabulário, simples e modesto, embora escrupuloso, que ele há de ser útil a estudantes e professores. E é nesse sentido que eu devo saudar como auspicioso o seu aparecimento [...].". Divide-se em: Introdução, Prefácio, os verbetes e as Referências Bibliográficas (149 pp.).

Brik (1978) - tem um capítulo: "Ritmo e sintaxe" (p. 131-139), na obra organizada por Boris Eikhembaum et al., intitulada Teoria da literatura: formalistas russos, Ed. Globo, no qual se posiciona quanto ao ritmo, que é empregado no sentido metafórico, imagético, despojado das significações artísticas que lhe foram emprestadas. Chama ritmo a toda a alternância regular, sem se importar com o que o alterna. No que diz respeito à sintaxe, que é o sistema de combinação de palavras no discurso cotidiano, entende que a língua poética não desobedece às leis principais da sintaxe prosaica, de modo que as leis da combinação de palavras são também as leis do ritmo. Portanto, o verso é a unidade rítmica e sintática primordial, concluindo que se deve compreender a língua poética no que a une e no que a distingue da língua falada: deve-se compreender sua natureza propriamente linguística. 
Paiva (1962) - A ironia é simultaneamente um estado espiritual e um processo típico de expressão. Essa atitude de espírito é a ironia em seu sentido amplo e o processo de expressão é a ironia em seu sentido restrito. Enquanto a definição de ironia como estado interior é de difícil delimitação, seu sentido específıco é mais conhecido: é a maneira de expressar per contrarium, ou seja, é a figura de retórica que atribui às palavras sentido contrário ao que usualmente expressam. Essas são considerações introdutórias ao livro de Maria Helena de Novais Paiva, Contribuição para uma estilística da ironia (Lisboa: Publicações do Centro de Estudos Filológicos, v. 12, 1961, 562 pp.). É um compêndio de conceitos e usos do termo ironia que, em seu sentido amplo, na linguagem cotidiana ou popular, assume forma de troça, mangação, graça e piada. A autora considera ironia o campo semântico comum dos termos que são parcialmente seus sinônimos e classifica os vários tipos de ironia: ironia pura, sátira, ironia disfemística, ironia restritiva e ironia contornante. Também faz uma exaustiva subclassificação de termos semanticamente relacionados à ironia e exemplifica através de textos literários de alta qualidade, em nome da construção de um quase tratado da estilística da ironia. Além disso, a afirmação da autora de que a ironia é uma atitude eminentemente social (pelos temas e pela atitude de diálogo) torna sua abordagem do assunto bem atual.

Pimpão (1942) - tem o ensaio de estética literária: "A expressão do 'cómico' em Eça de Queiroz" (p. 249-266), na revista Brotéria, Lisboa, vol. 34, 1942. Define Eça como um grande expressionista do cômico, faceta essencial e que melhor o define, a que mais acentuou, até se converter num modo exclusivo de ver a realidade, a ponto de o escritor ter definido a própria estética nestes termos: "um dos fins da arte realista é obrigar a ver verdadeiro", isto é, a ver cômico. Verifica que nada resiste à sua vontade de cômico: nada, nem mesmo a morte. Além disso, percebe que Eça possui o gênio da expressão caricatural e sabia notar como ninguém, na fisionomia, na atitude de uma personagem, o convencionalismo da lei social. Assim, não é difícil descobrir a influência das doutrinas evolutivas no espírito Eça e a crença no Progresso indefinido, que o levariam necessariamente a descobrir o cômico em toda a sociedade, instituição ou indivíduo que se lhe apresentasse com caráter estático. Por isso, conclui que o realismo de Eça não é, em grande parte, senão a intuição artística do que há de extrínseco e de mecânico num universo em perpétua transformação, de modo que "o riso é uma filosofia de vida". Cita que, em A Correspondência de Fradique Mendes, dá-se um fenômeno curioso sob o ponto de vista expressivo: o prefaciador, historiando as suas relações com o poeta das Lapidárias, consegue não só fazer rir do seu embaraço, mas ainda fazer sorrir da convenção que o provocou. Há como que uma espectralização do lance cômico.

Toda bibliografia consultada e aqui citada foi o con-texto que dirigiu a construção e a importância do artigo na produção do discurso. O estudo de um texto de Eça de Queiroz (s/d) - a carta "Ao Sr. E. Mollinet", em "A Correspondência de Fradique Mendes" - foi o campo que permitiu analisar as funções e a significação do artigo neste paper, bem como a estrutura proposta por Cressot (1969) e Paiva (1962) ao colocar a caracterização em seguida ao estudo do artigo. 
O fio nervoso da caracterização discursiva é conduzido pela inserção ou supressão do artigo: o Pacheco / Pacheco, que produz discursos distintos, construtores do cômico, contextuado pelo emprego do artigo na construção discursiva. São dois discursos em um só texto. Como lê-lo? O Pacheco, com realce irônico, ou Pacheco, com enfoque crítico?

Caracterizar é distinguir e definir o objeto; é ao mesmo tempo pôr em evidência aqueles factores que o diferenciam aos olhos de quem fala; por isso a caracterização participa da objetividade dos elementos extrínsecos ao sujeito, e da subjetividade do conhecimento e da atribuição. (PAIVA, 1961, p. 231).

Este texto propõe discutir o uso e a função do artigo sob o ponto de vista mórfico e sintático (MACAMBIRA, 1974; CRESSOT, 1969), bem como sua funcionalidade dentro do texto: a superlativação, a enfatização, a entoação.

Sob o ponto de vista mórfico, Macambira (1974) indica que o artigo não tem forma especial que o distinga como classe gramatical; assume as flexões de gênero e número que não são classificatórias, pois são comuns ao substantivo, ao adjetivo, ao pronome e ao numeral, e no aspecto sintático, as formas presas "o/a/os/as" e "um/uma/uns/umas", que imediata ou mediatamente precedem o substantivo, e com ele formam sintagma. A superlativação de uma qualidade pode ser feita por um artigo indefinido de valor enfático anteposto ao substantivo. A função enfática do indefinido é particularmente clara, quando ele aparece na frase exclamativa em expressões que, na proposição assertiva, o não emprega.

Para Cressot (1969), as palavras que nos são fornecidas pela linguagem - digamos, pelo dicionário para evitar qualquer ambiguidade - não representam os seres, mas seus conceitos. Então, para usar as palavras efetivamente na comunicação, precisamos transformar esses conceitos em seres. Este resultado é obtido por meio de duas operações que se complementam, às vezes simultaneamente, designadas sob os nomes de determinação e atualização.

Determinação. - "Determinar um objeto ou um ato é dar a ele uma figura individual através de um elemento, explícito ou implícito, que o distingue de outros objetos ou outros atos da mesma ordem. Quase exatamente, essa definição pode ser aplicada à caracterização: [...] a diferença está em uma atitude de esperança, não em uma questão de forma. (CRESSOT, 1969, p. 107, tradução nossa).

4 No original: « Détermination. - « Déterminer un objet ou un acte, c'est lui donner figure individuelle grâce à un élément, explicite ou implicite, qui le distingue d'autres objets ou d'autres actes du même ordre. ». A peu de chose près, cette définition pourra s'appliquer à la caractérisation : [...] la différence réside dans une attitude d'esprit, non dans une question de forme. ». 
Atualização. - Além da determinação, o substantivo e o verbo precisam ser atualizados. $O$ verbo, por suas formas pessoais, temporais, modais, nominais. Por definição, o infinitivo não é atualizado, mas o sistema sintático que o anexa ao restante da frase pode contribuir para uma atualização parcial. (CRESSOT, 1969, p. 108, tradução nossa ${ }^{5}$.

Por sua vez, Brik (1978) relata que a entoação faz o papel de caracterizador intenso. 0 artigo cria também uma função rítmica e tem um papel intensificante em nível entoativo, uma vez que o acento tonal reforça o conteúdo substantivo. Vejamos alguns exemplos em que aparece em meio de advérbio e substantivo: "nem uma obra"; "nem uma fundação"; "nem um livro"; "nem uma ideia"; nessas citações, o numeral, com ausência do qualificativo toma-lhe o lugar e opera como intensificador e pode superlativar todo um sintagma fraseológico. Assim, podemos, através desse tipo de artifício, modular um tom neutro por meio de um elemento superlativante, passando-o ao entoativo e exclamativo.

O artigo é dentre as categorias gramaticais uma das mais expressivas, porém nem sempre explorado. Alguns autores tiram-no da passividade e dão-lhe um tom aguerrido e múltiplo. A presença do artigo definido traz reforço aos nomes abstratos pluralizados, acentuando-Ihes a vaguidade; assim como sua omissão esvazia as arestas de nomes concretos, gerando sigmatização. E um texto produzido por meio de uma pontuação lógica, ausente o sistema afetivo, traduz tons afetivos, tons intensivos, se manipuladas habilmente as estruturas mórfico-sintáticas.

\section{Funções e usos do artigo}

Para distinguir e definir o artigo, é necessário caracterizá-lo, pois, conforme o entendimento de Paiva (1961, p. 231), "a caracterização envolve uma relação entre a pessoa que caracteriza e o mundo caracterizado e, em consequência, a projeção sobre este de um modo de ser individual, capaz de valoração afetiva alteradora.".

Após tais considerações, faremos uma incursão pela carta "Ao Sr. E. Mollinet", da obra de Eça de Queiroz (sd): "A Correspondência de Fradique Mendes", para examinar o artigo sob o aspecto morfossintático.

É comum em Eça o sigma indefinidor, diluidor de contorno. Partículas, substantivos, adjetivos, advérbios são substitutos do aumentativo superlativante; até mesmo a palavra "um", em singular, suporta a significação esvaziadora. Vejamos como, nos dois primeiros

5 No original: « Actualisation. - En plus de la détermination, le substantif et le verbe exigent d'être actualisés. Le verbe l'est par ses formes personnelles, temporelles, modales, aspectives. Par définition, l'infinitif est inactualisé, mais le système syntaxique qui le rattache au reste de la phrase peut contribuer à une actualisation partielle. ». 
parágrafos da carta, a construção textual revela-se ao confrontarmos a segunda arquitetura paragráfica com a primeira, conforme indicação de página, parágrafo e linha:

[...] saber que obras, ou que fundações, ou que livros, ou que ideias, ou que acréscimo [...] (p. 1064, 1º, 6).

e

[...] não deu ao seu país nem uma obra, nem uma fundação, nem um livro, nem uma ideia. (p. 1064, 20 2).

A partícula "que", integrante do verbo, além de conectivo, introdutor de interrogação indireta, contextualmente é pronome indefinido, acompanhante dos substantivos pluralizados. Observa-se o singular na última palavra da enumeração, acréscimo, uma espécie de concretização frente a todas as indefinições quantitativas da série nominal.

No segundo parágrafo, retomando a ideia do anterior, responde, Fradique, à questão numa série de substantivos no singular, porém tornados indefinidos pelo artigo. Ainda, neste fragmento, e em outros, joga com dois nomes (profundidade, eminências) abstratos pluralizados. É o plural diluidor de contornos:

\author{
[...] recolhido, nas profundidades de Pacheco! (p. 1064, $\left.2^{\circ}, 8\right)$. \\ [...] através das instituições [...] (p. 1064, 20, 20$)$. \\ [...] não prodigalizou desde logo os seus tesouros [...] (p. 1065, 4º, 19). \\ [...] durante os longos meses de gerência [...] (p. 1066, 6º, 5).
}

Não se desvia da posição criadora quando manipula os graus, nosso escritor foge das normas do padrão culto, e usa adjetivos, com funções adverbiais superlativando por meio de partícula fônica e sintaticamente intensivas: "[...] está sendo tão vasta e amargamente carpida [...]" (p. 1064, 10, 5); "[...] seguindo ao túmulo por tão sonoras [...]" (p. 1064, 10, 8); "[...] aquele talento, sendo tão vasto - era ao mesmo tempo tão fino!" (p. 1067, 11º, 12).

Em: "E deseja ainda o amigo saber [...]" (p. 1064, 10, 6) a partícula "ainda", em função adverbial, dá energia ao verbo "deseja", pondo-o num grau mais alto que a pergunta da frase anterior.

Macambira (1974, p. 47) menciona que a "inclusão do artigo e do numeral na classe do pronome não é iniciativa nossa, e, se a esposamos, é premido pelas circunstâncias que o fazemos.". A seguir, cita o dinamarquês Jespersen, que muito o teria impressionado: 
Os numerais são muitas vezes considerados como distinta classe de palavra; seria provavelmente preferível tratá-los como subclasse dos pronomes, com os quais têm muitos pontos em comum. One, além de ser numeral, é pronome indefinido em inglês, bem como outros idiomas (One, never knows = nunca se sabe); outro tanto pode ser dito sobre a combinação oneself. [Em castelhano existe o pronome uno - se: nunca sabe uno = nunca se sabe.] A forma fraca de one é o chamado artigo indefinido, e se a contraparte - o artigo definido - é com razão contato entre os pronomes, o mesmo devia dar-se com o inglês $a$, an, o francês un e assim por diante. Estabelecer classes separadas para os dois artigos, como se faz em algumas gramáticas, é irracional. (JESPERSEN, apud MACAMBIRA, 1974, p. 48).

Por essa razão, como já mencionamos, Borba (1971, p. 42) aponta que o artigo é um categorema, informando que "Benveniste usa o termo no sentido de predicação e propõe substituí-lo por frasema".

Debrucemo-nos, agora, sobre os estudos de Cressot (1969) sobre o Artigo; pois, segundo o linguista francês, os objetos se apresentam à nossa percepção às vezes como massas descontínuas, individualizáveis, mesa, casa, árvore; ou como massas contínuas, manteiga, leite, mas deve-se levar em conta que podem ocorrer interferências entre as duas séries; eu posso dizer: um pão, do pão; ele tem um vício, do vício.

Se for um ou mais objetos específicos para o falante e para o destinatário da declaração, a atualização é feita usando o artigo definido; caso contrário, por meio do indefinido (o livro de Paulo, um livro).

Essa situação proposta por Cressot ocorre na carta "Ao Sr. E. Mollinet", uma vez que nela a postura discursiva constrói a relação Fradique / Mollinet / Povo, isto é, entre o destinatário e o emissor, consoante constatamos nos dois primeiros parágrafos e registramos acima.

O artigo é dentre as categorias gramaticais uma das mais expressivas, porém nem sempre explorado; todavia, Eça de Queiroz tira-Ihe da passividade e dá-Ihe um tom aguerrido e múltiplo.

No processo nominalizador, a carta "Ao Sr. E. Mollinet" joga com dois nomes: Pacheco e talento, que aparecem frequentemente formando com "imenso" o sintagma temático, para o qual confluiu toda tapeçaria linguística. Nesses compactos, o artigo definido mostra toda sua força estilística, indicadora dos níveis de discurso. Assim, Pacheco / o Pacheco são discursos distintos, como o são: o meu douto amigo / este meu compatriota.

Pela descrição do artigo podemos verificar três posições básicas dos interlocutores discursivos: 1. a de Fradique Mendes em relação a Pacheco; 2. a do povo em relação a 
Fradique; e 3. a de Fradique em relação ao povo. Eça consegue realizar o distanciamento usando ou omitindo o artigo, antes do nome do personagem-chave. Ora lê-se Pacheco, ora lê-se o Pacheco. A presença ou omissão não é gratuita. As nuances do manejo morfêmico do artigo redundam em uma afetividade, familiaridade, carinho, proximidade e/ou resulta em distanciamento, frieza e desconhecimento. Por duas vezes, Fradique escreve na carta "o Pacheco" e sabemos que essa voz não é sua, mas do povo. Nas cinquenta e duas vezes em que o nome do Conselheiro aparece desacompanhado do artigo, a emissão indica que essa voz é de Fradique Mendes.

Para Cressot (1969), o artigo definido aparece, com determinação explícita ou implícita, assim que a mente concebe o objeto em si e para exclusão de qualquer outro da mesma ordem. Essa exclusividade lhe confere o que os gramáticos chamam de notoriedade, um termo que não é inútil especificar para evitar qualquer mal-entendido e que implica que o objeto é conhecido do falante, do falante e do destinatário, ou conhecido em geral: o Pacheco x Pacheco.

Por sua vez, o artigo indefinido atualiza um objeto retirado de um conjunto de objetos de mesma ordem. Às vezes com total indiferença, e.g.: empresta-me um livro, e, neste caso, o artigo pode ser reforçado por qualquer um. Algumas vezes com um começo de determinação vagamente implícito, e.g.: um cordeiro foi saciar-se..., um lobo surgiu (obviamente não é sobre qualquer cordeiro, qualquer lobo, mas personagens da história, mas nós não sabemos mais nada). Outras vezes, com uma preocupação pela discriminação, e.g.: um lindo sol brilhava em um céu sem nuvens. Este sol e este céu se opõem a outros sóis, outros céus que não têm essa qualidade. Este valor discriminante nos leva naturalmente a um valor de relevo.

A presença do definido traz reforço aos nomes abstratos pluralizados, acentuando-lhes a vaguidade; assim como sua omissão esvazia as arestas de nomes concretos, gerando sigmatização. Desse modo, buscamos, exaustivamente, essas construções na carta:

\footnotetext{
[...] nas profundidades de Pacheco! (p. 1064, $\left.2^{\circ}, 8\right)$.

[...] através das instituições [...] (p. 1064, 20 $\left.{ }^{\circ}, 20\right)$.

[...] das riquezas interiores [...] (p. 1065, 40 , 11).

[...] desdenhoso das especialidades. (p. 1066, 50, 2).

[...] os interesses supremos [...] (p. 1066, 60 10$)$.

[...] nos jornais de Portugal. (p. 1064, 10, 5).

$[\ldots]$ os amigos $[\ldots]$ (p. 1064, $\left.2^{\circ}, 16\right)$.

[...] os partidos [...] (p. 1064, $\left.2^{\circ}, 16\right)$.

[...] as repartições [...] (p. 1064, 20 ${ }^{\circ}$ 16).
} 


\author{
[...] os movimentos religiosos [...] (p. 1065, $\left.3^{\circ}, 6\right)$. \\ [...] dos rapazes aos lentes [...] (p. 1065, 30,7). \\ [...] todos os olhares [...] (p. 1065, 4⿳0,7). \\ [...] os conselhos da Coroa. (p. 1066, 60, 1). \\ [...] nas câmaras, nas comissões, nos centros [...] (p. 1066, 70, 6).
}

Aqui já não se tem o indefinido - sim o numeral que, além da função rítmica, tem um papel intensificante em nível entonativo uma vez que o acento tonal reforça o conteúdo substantivo. Vejamos alguns exemplos em que aparece em meio do advérbio e substantivo: "[...] nem uma obra, nem uma fundação, nem um livro, nem uma ideia." (p. $\left.1064,2^{\circ}, 2\right)$.

Nessas citações, o numeral, com ausência do qualificativo, toma-lhe o lugar e opera como intensificador e pode superlativar todo o sintagma fraseológico. Assim, podemos, através desse tipo de artifício, modular um tom neutro por meio de um elemento superlativante, passando-o ao entonativo e exclamativo. E um texto produzido por meio de uma pontuação lógica, ausente o sistema afetivo, traduz tons afetivos, tons intensivos, se manipuladas habilmente as estruturas fônico-sintáticas.

Cressot (1969) expõe, ainda, a concorrência dos três artigos, exemplificando que nós dizemos: ele tem a tifoide, ele tem uma tifoide, ele tem sintoma da tifoide. Assim, o definido enfatiza que esta é uma doença conhecida ou temida (notoriedade). O indefinido elimina essa nota, banaliza o fato; ele pode, num certo sentido técnico, determinar uma variedade da doença. O artigo partitivo evoca um grau vago na evolução desta doença. Podemos identificar essa situação na carta: "[...] na manhã em que Pacheco, desdenhando a Sebenta, assegurou que "O século XIX era um século de progresso e de luz»." (p. 1064$\left.1065,3^{\circ}, 2\right)$.

\title{
Os vários níveis do discurso
}

O texto da carta ora analisada é um conjunto de diversos discursos, embora dirigido a um destinatário (Sr. Mollinet), e emanado de um produtor (Fradique Mendes). Há várias perspectivas, uma vez que os referentes (Pachecopovo) deslocam-se e o narrador ajusta os níveis de linguagem a ópticas diversas. As marcas distintivas encontram-se: no sentenciosismo; nas vozes proferidas pelo discurso direto; na manipulação do artigo; na permeabilidade léxica.

a) O sentenciosismo é marcado pelas frases óbvias, que Eça usa na carta como subsídio intensificador da ironia e, colocado na boca de Pacheco o qual, segundo entendimento popular, era homem de profundo conhecimento, vai revelando ao leitor o falso talento 
do protagonista: "[...] «que ao lado da liberdade devia sempre coexistir a autoridade!»" (p. 1065, 40, 21); "[...] «O talento verdadeiro só devia conhecer as coisas pela rama»." (p. 1066, 50, 10); "[...] «um povo sem o curso dos liceus é um povo incompleto»." (p. 1066, $\left.7^{0}, 13\right)$.

Corroborando esse entendimento, Pimpão (1942, p. 250) menciona que "Eça não hesita em tornar cômica a destruição física do homem", como podemos citar o trecho da carta: "Rebentou; - quero dizer, S. Ex. ${ }^{a}$ morreu [...]" (p. 1067, 12º, 1).

Pimpão (1942, p. 252) também argumenta: "Note-se, de passagem, o emprego insistente do imperfeito do indicativo [...] e que aqui não serve de exprimir a vida habitualmente vivida, mas acentua, prolonga o efeito cômico da cena.". Na carta, Fradique refere-se a Pacheco: "À maneira que ele assim envelhecia, e crescia em influência e dignidades [...]" (p. 1067, 90, 1).

Continua Pimpão (1942, p. 253): "As ideias ou sentimentos convencionais tornam-se mais visíveis, mais fáceis de notar, quando traduzidas numa linguagem intensa carregada de significação.". Sobre essa observação, encontramos na carta: "A sua velhice ofereceu um carácter augusto. Perdera o cabelo radicalmente." (p. 1067, 11º, 1).

Também mostra Pimpão (1942, p. 255) que o cômico pode estar na sutileza: "Nem sempre, porém, o cômico é visto por fora, na expressão rígida das palavras, dos tiques, dos gestos, das atitudes.". Fradique demonstra um distanciamento de Pacheco: "Eu casualmente conheci Pacheco." (p. 1064, 20, 1).

Evidenciando a comicidade do texto, Pimpão (1942, p. 258) propõe ainda que: "A linguagem viva pode, também, tornar-se cômica.". É o que se nota na carta: "A esses ouvi eu bradar com furor, atirando patadas ao chão: «Irra, que é talento de mais!»" (p. 1067, 90, 10).

b) As vozes proferidas através do discurso direto podem ser percebidas, quando colocamos as oposições, a partir do sentenciosismo, das frases óbvias ditas pelo Conselheiro e daquelas, em discurso direto, ditas pelos Conselheiros da Coroa e pelo povo em geral, conforme se infere dos seguintes excertos da carta:

«Parece que há agora aí um rapaz de imenso talento que se formou, o Pacheco!» (p. 1065, 30, 16).

«É o Pacheco, rapaz de imenso talento!» (p. 1065, 4º 6).

«Nem é necessário mais! Basta ver aquela testa!» (p. 1066, 4º 33).

[...] «está à espera, lá em cima, a pairar» (p. 1066, 5º,7). 


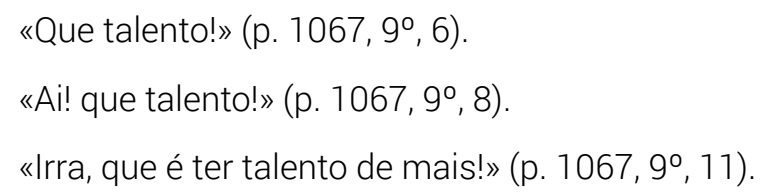

c) Destacamos a manipulação do artigo ao referir-se ao Sr. Mollinet, a série possessiva de primeira pessoa, com ou sem artigo definido anteposto, seguido do adjetivo, igualmente anteposto afetivamente ao substantivo, resulta uma invariante, quase um clichê, como se lê no texto de Eça em análise:

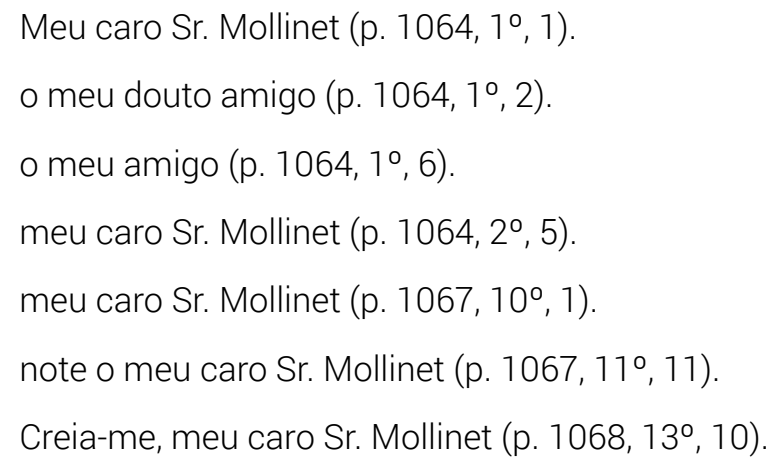

Porém, ao citar o Conselheiro Pacheco, o tratamento é distanciado, objetivo, apenas referencial. Leia-se pelos parágrafos $1^{\circ}, 2^{\circ}, 3^{\circ}, 4^{\circ}$ : Pacheco. 0 único grafema a acompanhálo é o demonstrativo anafórico este (Pacheco) - esse (Pacheco). Lado outro, o discurso do povo, infiltrando o de Fradique diferencia-se no parágrafo 4º linha 6: o Pacheco.

d) Quanto à permeabilidade léxica na carta, há uma nítida marca individual para cada referente, formalizando um léxico adequado ao nível intelectual dos interlocutores. As formas binárias e ternárias registram permeabilidade do distenso ao tenso, criando um ritmo composicional que, segundo Brik (1978, p. 135): "a união indissolúvel do ritmo e da semântica é o que chamamos geralmente de harmonia clássica de Pushkin.". Apontamos no esquema abaixo essa constatação:

$\begin{array}{lll}\mathbf{a} \text { (tenso) } & & \mathbf{b} \text { (distenso) } \\ \text { sentia } & \text { e } & \text { saboreava }\left(p .1064,2^{\circ}, 23\right) \\ \text { repleto } & \text { e } & \text { fecundo }\left(p .1066,7^{\circ}, 2\right) \\ \text { lapidária } & \text { e } & \text { suculenta }\left(p .1066,7^{\circ}, 12\right)\end{array}$

Alguns verbos com significação concreta, empregados para ações abstratas, ou sujeitos e complementos, surgem da oralidade. Partículas "e", "então", "ainda", "como" infiltram-se matizando de fala popular o discurso: "[...] teve um movimento como para atalhar [...]" (p. 1065, 40, 13). 
Para um mesmo referente, retomando-o, varia o léxico, alterando o nível, no que tange à atitude de relacionar-se a Pacheco: "[...] Pacheco teve um movimento como para atalhar um padre zarolho que arengava sobre a liberdade." (p. 1065, 4, 13); "O sacerdote imediatamente estacou com deferência [...]" (p. 1065, 4º , 14).

Observe-se: "padre zarolho" e "sacerdote"; "arengava" e "estancou com deferência" - o gestual em relação ao Pacheco, daí a mudança lexical.

Por fim, ao registrar: "Rebentou; - quero dizer, S. Exa. morreu [...]" (p. 1067, 12 , 1), a informalidade e a ação real atribuída ao Conselheiro é "rebentou", mas o destinador da carta "Ao Sr. E. Mollinet", ao sentir o desvio, corrige-o para "morreu", formalizando a norma prescritiva, eis uma das marcas da ironia.

Eça, ao escrever esta carta, registrou notável acuidade linguística. A linguagem viva, oral, está presente; ainda que certo tom retórico, adequado à construção da figura de Pacheco, semeie todo um ritmo bombástico a certas construções que traduzem por inteiro o Conselheiro. À perspectiva de exemplos demais citados, inserido no seu contexto verbal representativo, tem igualmente sua marca no discurso.

Os registros dos vários interlocutores obedecem a faixas sociais. Assim o do povo em relação a Pacheco; o de Fradique como emissor do discurso; o de Pacheco; o do deputado dessemelham todos do Sr. Mollinet. Logo, cada fato, cada referente, sofre variações léxicas e até mesmo sintáticas, na tentativa de apreender na fonte o discurso.

Cumpre-nos, ainda, notar que a carta "Ao Sr. E. Mollinet" possui duas formas discursivas: descritiva e narrativa, com domínio da função referencial e, em pleno adjuvante, a função metalinguística e a função fática. Contudo, parece-nos que nas entrelinhas o desempenho maior cabe à função apelativa e que só a análise da entonação pode levar-nos a descobrir o grande poder da função poética, tão subjacente quanto à apelativa.

\section{Posição das personagens do discurso}

A representação na memória, que se fazem Mollinet e Fradique; as relações de intersubjetividade e relações inter-humanas existentes entre estes destinadores e destinatários é um bom começo para se cuidar das condições de produção deste texto.

A carta em questão é gerada de duas perguntas do destinador Mollinet ao destinatário Fradique: quem é Pacheco, tão chorado post mortem, em Portugal? Que obras, que fundações, que livros, que ideias, que acréscimo deixou à civilização portuguesa? 
Fradique, já destinador, informa ao Sr. Mollinet, então destinatário, quem é Pacheco. A informação será o seu ato linguístico básico: um ato assertivo; - o destinatário irá saber do destinador o que ele conhece e em que acredita.

Dentro do esquema informacional, Pacheco será o referente; Fradique, o destinador; e Mollinet, o destinatário. Assim, pressupõe-se que sucedem estas indagações entre os protagonistas, decorrentes do esquema:

\author{
JUNTO DE FRADIQUE - A \\ - Quem sou eu para falar assim ao Sr. Mollinet? \\ - Quem é o Sr. Mollinet para eu Ihe falar assim? \\ - De que lhe falo eu? \\ - De que ele me fala? \\ - O que pretendo de mim falando ao Sr. Mollinet dessa forma? \\ - 0 que pretendo dele falando-Ihe desta forma? \\ JUNTO AO SR. MOLLINET - B
}

- Deve apresentar as mesmas indagações, pois as condições gerais de produção são partes essenciais e constitutivas dessa sequência verbal dotada de sentido advinda dos protagonistas, da situação, do contexto histórico-social.

\title{
PROTAGONISTAS
}

FRADIQUE, perfilado na "Correspondência" como personagem de Eça de Queiroz, é português, culto, filósofo, de posição social elevada, rico, original, viajado, quase um sábio, enfim.

SR. MOLLINET, pincelado brevemente por Fradique, francês, diretor da Revista de Biografia e História, douto.

PACHECO, objeto da referência do Sr. Mollinet, é um português falecido recentemente, chorado pela nação portuguesa, idolatrado pelo povo - conhecido casual de Fradique.

Todos pertencem a um mesmo contexto econômico-social, com um desnivelamento ideológico de Pacheco. Estas igualdades e diferenças vão atuar sobre o jogo do discurso: estratégias e imagens; atos da linguagem e imagens e atos. 
O texto é uma carta-resposta. Pois bem, em que bases de relações sociais Mollinet indagaria de Fradique sobre Pacheco? Já teria algum ponto de vista sobre Pacheco? Necessitaria de informações complementares? O primeiro parágrafo elucida as inquirições. Ambos - Fradique e Mollinet - estão na França; as interrogações decorrem do interesse pessoal do Diretor da Revista e da própria Revista de Biografia e História. A relação entre os protagonistas é cordial e informal: Fradique para Mollinet: - "Meu Caro Sr. Mollinet [...] meu douto amigo [...]" (p. 1064, 10, 1 e 2).

Como evidencia o estilo indireto desse primeiro grupo de orações, manifestado pelo ato ilocucional, algum ponto de vista, implícito no perlocucional, de Mollinet sobre Pacheco, seu compatriota. Mollinet refere-se a Pacheco:

[...] me pergunta quem é este meu compatriota Pacheco (José Joaquim Alves Pacheco), cuja morte está sendo tão vasta e amargamente carpida [...] deixou esse Pacheco [posição longe de Mollinet] seguido ao túmulo por tão sonoras, reverentes lágrimas. (p. 1064, 10,3).

Tanto a relação social como a atuacional já se esclarecem pela implicitação enunciativa, cujo sous-entendu volitivo diluia agressividade de Fradique contra Pacheco, estabelecendo, porém, pressupostos para o ato de linguagem, imagens e estratégias. Já há uma posição assumida pelo destinador quanto ao discurso. Tal qual Mollinet, Fradique navegará pela linha da enunciação velada, porquanto comunga da mesma ética e ideologia.

O que deseja, pois, o protagonista B - Sr. Mollinet - do protagonista A - Fradique? Informações sobre Pacheco. Quem sou eu para Ihe falar assim? Seu amigo é Diretor da Revista de Biografia e História. Quem é ele para eu Ihe falar assim? Fradique Mendes, culto e internacional, meu amigo; os papéis sociais estão, logo, definidos no segundo parágrafo da carta. Tem começo a linha narrativo-descritiva: "Eu casualmente conheci Pacheco." (p. 1064, 20, 1), que pontua e acrescenta um aspecto à terminalidade com o próprio texto. Já, então, Fradique investe-se de locutor, enquanto o Sr. Mollinet ficará na condição de ouvinte.

O eixo inquiritivo desloca-se para Fradique:

INTERLOCUTOR A

- Quem sou eu para lhe falar assim?

- O que pretendo dele falando-Ihe dessa forma?

Fradique apresenta-se como um português cumpridor dos deveres pátrios, mas discordante da ideologia nela implantada; consciente de seus poderes e limitações, analisa em sua "Correspondência" as posições culturais da nação lusitana. O seu saber, 
o seu universalismo autorizam-no a acometer os modelos coletivos herdados, acometer a impotência crítica dos valores insignificantes e areentos.

O Sr. Mollinet, no primeiro parágrafo, ao escrever a Fradique, dá-lhe o tom da inflexão. A partir do segundo, ele, Fradique, harmoniosamente, retoma-o e se lhe ajusta. Ambos afirmam-se quanto ao jogo do discurso.

De uma pergunta espera-se a resposta. E ela virá explicitada, modulada ao tipo de enunciação da realidade discursiva. A pretensão da fala de Fradique é atuável. E a notícia sobre Pacheco não se constrói inocentemente, mas com grande força de intencionalidade. Se a posição de Fradique, como português amante da pátria, impede-lhe de ajuizar o fenômeno Pacheco, não Ihe impede de, manipulando a linguagem reversa, ajuizar e atuar sobre Mollinet com o ne pas dire. A estratégia, pois, do jogo do discurso é a implicitação - técnica da diatribe.

\title{
Ritmo criado pelo uso do artigo
}

Geralmente chama-se ritmo a toda alternância regular; e não nos interessa a natureza do que alterna. O ritmo musical é a alternância dos sons no tempo. O ritmo poético é a alternância das sílabas no tempo. O ritmo coreográfico, a alternância dos movimentos no tempo. [...] Em suma, falamos de ritmo em toda a parte por onde podemos encontrar uma repetição periódica dos elementos no tempo ou no espaço. (BRIK, 1978, p. 131).

O planeamento do artigo cria um ritmo, quando evidencia o relacionamento íntimo entre destinatário e referente - Pacheco - se confrontando com o do povo. Vejamos:

a) o tratamento de Fradique para como o destinatário:

\author{
Meu Caro Sr. Mollinet (p. 1064, 1º I. 1); \\ o meu douto amigo (p. 1064, 10, I. 2); \\ o meu amigo (p. 1064, 10, I. 6); \\ meu caro Sr. Mollinet (p. 1064, 2, I. 5); \\ o meu caro Sr. Mollinet (p. 1067, 10, I. 1); \\ o meu caro Sr. Mollinet (p. 1067, 11 ${ }^{\circ}$, I. 11); \\ meu caro Sr. Mollinet (p. 1068, 13ㅇ, I. 10).
}


b) o tratamento de Fradique para como o referente Pacheco (quarenta e oito vezes);

c) o tratamento de outros protagonistas para com o referente o Pacheco (duas vezes);

d) o tratamento do Sr. Mollinet dado ao referente: "[... este meu compatriota Pacheco $[\ldots]^{\prime \prime}($ p. 1064, 10, 4) e "[...] esse Pacheco [...]" (p. 1064, 10, 8).

Esta tabulação nos revela: a afetividade de Fradique para com o destinatário versus o distanciamento para com o referente; a deferência versus a negligência, tudo montado a partir do enunciado, que retomamos: "Eu casualmente conheci Pacheco." (p. 1064, 20, 1).

Entretanto, do povo nos chega um outro grau: o Pacheco (p. 1065, 30 17 e 4º 6), afetivo, próximo. De Mollinet, o ponto de vista acerta-se com Fradique: "este Pacheco" e "esse Pacheco" (p. 1064, 10 4 e 8).

Ora, viemos afirmando por nossa explanação a intencionalidade elaborativa, pretendendo graduar e pluralizar o discurso, ato plenamente atingido pela prismática referencial. Logo, a voz que emite Pacheco é a de Fradique e ela se situa no plano do subentendido enunciativo; a que emite o Pacheco é da "massa compacta da nação" (p. 1064, 20, 17) e ela se explicita no ato da enunciação. Suas posições na perlocução: a da implicitação e a da explicitação. Aquela, por subtrações e convenções, recolhe-se ao velamento, porém, tendo as imagens do seu ouvinte, pode produzir um tipo de discurso que será decodificado na sua integralidade. Esta, inserida no prescrito, atua no nível do explícito.

\section{Considerações finais}

Surte desse refletir a afirmação que tal uso eciano do artigo permite entrever tons e vozes do discurso, junto às formas de tratamento que contraem um contexto e indiciam a situação da condição de produção destacadas.

A carta de Eça é uma provocação ao leitor estudioso de textos, pois a maneira como utiliza o artigo, ora suprimindo, ora inserindo, cria dois discursos num só texto, propõe uma nova metodologia construtiva, mistura vozes, determina a tessitura e novos caminhos para a leitura. 


\section{REFERÊNCIAS}

BENVENISTE, É. Problèmes de Linguistique Générale. Paris: Gallimard, 1966.

BOLÉO, M. de P. O realismo de Eça de Queiroz e a sua expressão artística. Biblos, Coimbra, n. 17, p. 697-731, 1941.

BORBA, F. da S. Pequeno vocabulário de linguística moderna. São Paulo: Nacional; EDUSP, 1971.

BRIK, O. Ritmo e sintaxe. In: EIKHENBAUM, B. et al. Teoria da literatura: formalistas russos. Porto Alegre: Globo, 1978. p. 131-139.

CRESSOT, M. Le style et ses techniques: précis d'analyse stylistique. 6. ed. Paris: PUF, 1969.

MACAMBIRA, J. R. A estrutura morfo-sintática do português: aplicação do estruturalismo linguístico. 2. ed. São Paulo: Pioneira, 1974.

OLIVEIRA, M. M. M. de. Processos de intensificação no português contemporâneo. Lisboa: Publ. do Centro de Estudos Filológicos, 1962.

PAIVA, M. H. N. Contribuições para uma estilística da ironia. Lisboa: Publ. do Centro de Estudos Filológicos, 1961.

PIMPÃO, A. J. da Costa. A expressão do "cómico" na obra de Eça de Queiroz. Brotéria, Lisboa, v. 34, p. 29-266, 1942.

QUEIROZ, E. A Correspondência de Fradique Mendes - VIII Ao Sr. E. Mollinet. In: QUEIROZ, E. Obras Completas. v. II. Porto: Lello \& Irmão Editores, s/d. p. 1064-1068. 